\title{
INSTRUTORES E APRENDIZES DO CURSO DE MECÂNICO DE MANUTENÇÃO DO SENAI-RJ: PERCEPÇÕES E REPRESENTAÇÕES SOBRE AS NOVAS HABILIDADES REQUERIDAS E A NOVA GRADE CURRICULAR NOS ANOS DE 1990'
}

\author{
Mônica Paranhos ${ }^{2}$
}

\section{Introdução}

O nosso interesse primordial consistiu em analisar como foi realizada a formação do trabalhador polivalente oferecida pelo Serviço Nacional de Aprendizagem Industrial (SENAI) $^{3}$, do Rio de Janeiro, Brasil, na década de 1990. Escolhemos o então chamado curso de nível básico (antigo curso de aprendizagem destinado aos jovens de 14 a 18 anos) de mecânico de manutenção da indústria metalmecânica ${ }^{4}$ como parâmetro para mapear os princípios e valores que estavam permeando a formação profissional destes trabalhadores.

\footnotetext{
${ }^{1}$ Este artigo é uma versão modificada de dois capítulos da minha dissertação de mestrado defendida no PPGSA-IFCS-UFRJ , intitulada A construção do novo trabalhador industrial do SENAI-RJ e sob orientação da Professora Elina Pessanha.

${ }^{2}$ Universidade Federal do Rio de Janeiro, Brasil.

${ }^{3}$ O Serviço Nacional de Aprendizagem Industrial (SENAI) foi criado em 1942 pelos empresários brasileiros, durante o governo de Getúlio Vargas, cuja principal política econômica foi o fomento do desenvolvimento industrial. Na década de 1940, Getúlio Vargas determinou que Euvaldo Lodi, presidente da Confederação Nacional da Indústria (CNI), Roberto Simonsen, presidente da Federação das Indústrias do Estado de São Paulo (FIESP) e Valentim Bouças, estudassem a criação de um organismo destinado ao ensino profissional dos aprendizes das plantas fabris. Os industriais apresentaram o projeto do Serviço Nacional de Seleção, Aperfeiçoamento e Formação dos Industriários (SENAFI), que mais tarde foi substituído pelo projeto do Serviço Nacional de Aprendizagem Industrial (SENAI). O SENAFI permitia a participação de representantes dos sindicatos operários nos órgãos diretores das instituições de ensino profissional, porém as instituições seriam subordinadas à Confederação Nacional da Indústria (CNI). O que foi oferecido aos sindicatos como contrapartida ao fato de terem se tornado atores secundários na formação profissional com a criação do SENAI foi o aceite da CNI em assumir os encargos da criação e a manutenção das escolas profissionalizantes. O principal ator social da formação profissional, o trabalhador, foi excluído de participar da implantação das escolas profissionais e da formulação da estrutura curricular dos cursos profissionalizantes. Vale ressaltar que até os dias de hoje, a gestão do SENAI continua somente sob a égide dos empresários e prossegue sendo a principal agência formadora de mão-de-obra para a indústria do país.

${ }^{4}$ Atualmente, esse curso corresponde à modalidade de habilitação técnica, destinada a alunos matriculados ou egressos do ensino médio, e pode, também, ser desenvolvido como aprendizagem industrial técnica, quando destinados a jovens com idade entre 14 e 24 anos, com contrato de aprendizagem com empresas, nos termos do art. 428 da Consolidação das Leis do Trabalho (CLT). O SENAI oferece os seguintes cursos para a indústria metalmecânica: técnico em construção naval, técnico em eletromecânica, técnico em mecânica, técnico em metalurgia e técnico em fabricação mecânica, na modalidade habilitação técnica ou aprendizagem industrial técnica. De acordo com as diretrizes do Programa Nacional de Gestão da Educação Profissional e Tecnológica do SENAI, bem como a Resolução CNE/CEB número 3, de 9 de julho de 2008, outros cursos podem ser ofertados em caráter experimental, com a possibilidade de serem incluídos, oportunamente, em novas edições do catálogo nacional de cursos técnicos do SENAI. Para maiores informações veja SENAI/ Departamento Nacional, 2010.
}

Iluminuras, Porto Alegre, v. 14, n. 33, p. 212-228, jul./dez. 2013 
Ao fazer o levantamento das novas diretrizes que foram inculcadas pela entidade, tivemos como escopo, também, analisar como os novos valores e princípios do capitalismo e da nova metodologia de ensino foram apreendidos pelos aprendizes e instrutores. A pesquisa foi realizada por meio da análise do material didático do curso de mecânico de manutenção, da observação de campo realizada durante todo o ano de 1999 e das entrevistas. No total foram realizadas treze entrevistas, sendo três com as técnicas da área de educação profissional do SENAI, quatro com os aprendizes do curso de mecânico de manutenção, três com os instrutores da área metal-mecânica da entidade, uma com um operário e ex-aprendiz (já na nova metodologia) do SENAI e duas com representantes das indústrias que mantinham aprendizes. No item I, nós descreveremos o material didático utilizado no módulo de habilidades de gestão. No item II, nós discutiremos as percepções e representações dos instrutores e aprendizes a respeito das mudanças no SENAI e no mundo do trabalho.

No início da década de 1990, o SENAI começou a discutir os rumos do trabalho industrial e, por conseguinte, a redefinição da formação profissional que era oferecida, tendo em vista as mudanças ocorridas na esfera da produção fabril, tanto em termos tecnológicos como no âmbito de gestão do trabalho. A partir do novo contexto econômico e das escolhas feitas pelo empresariado brasileiro, o SENAI se debruçou sobre o seu modelo de formação profissional e efetuou radicais mudanças. Os cursos profissionalizantes oferecidos pelo SENAI passaram por uma profunda transformação curricular e metodológica em 1995. Levando em conta estes preceitos gerais, o SENAI formulou o Projeto Logos, que estabeleceu uma nova metodologia e um novo currículo para os cursos profissionalizantes. Em 1995, o Projeto Logos contou com turmas pilotos dos cursos de aprendizagem, hoje denominados cursos básicos, com alunos entre 14 a 18 anos, nas áreas de metal-mecânica, construção civil e artes gráficas.

O Projeto Logos encerra o princípio normativo da racionalidade enfatizando a criatividade, o raciocínio lógico, a capacidade de interpretação das linguagens, os conceitos éticos e morais, o pleno exercício da cidadania, enfim os preceitos de uma educação digna e compatível com os anseios do progresso econômico e social que incorpora a polivalência profissional como pré-requisito (Senai-RJ-DE-DFP, 1994)

O perfil do trabalhador industrial demandado era composto pela polivalência, capacidade de decisão e de iniciativa, cooperação, autonomia, responsabilidade, 
criatividade e participação efetiva deste trabalhador no processo produtivo (Senai-RJ-DEDFP, 1994).

Sob a ótica do SENAI, a polivalência é entendida como:

O termo polivalente alude a uma nova formação que prepara o sujeito para o desempenho qualificado numa área ocupacional sobretudo para compreender as bases gerais-científico-técnicas e sócio-econômicas da produção do seu conjunto. Uma formação que conjugue a aquisição de habilidades e destrezas genéricas e específicas com o desenvolvimento de capacidades intelectuais e estéticas. Implica na aquisição de possibilidades do pensamento teórico, abstrato, capaz de analisar, de pensar estrategicamente, de planejar e responder criativamente a situações novas, como também, de desenvolver capacidades sócio-comunicativas que facilitem a realização de trabalho cooperativo em equipe (Senai-RJ, 1999a, p. 1-2).

$\mathrm{O}$ antigo método da instrução individualizada ${ }^{5}$, com a utilização intensa das séries metódicas ocupacionais, não estava mais respondendo às demandas das grandes empresas brasileiras e multinacionais com filiais no Brasil.

Para o Senai:

A concepção de educação profissional fundamenta-se, pois, num projeto educacional que tem em vista a formação de um trabalhador pleno cidadão, capaz de atuar de forma crítica, consciente, participativa, com mobilidade e flexibilidade, tanto na vida cotidiana quanto no mundo do trabalho; incorpora e integra os conteúdos específicos aos atributos necessários à qualificação do sujeito, inter-relaciona, para isso, conteúdos de formação geral e de formação profissional, de modo a possibilitar a inserção crítica do trabalhador na cultura de seu tempo. Seus pressupostos básicos são a construção da cidadania, a visão de totalidade do ser e do mundo, o desenvolvimento das múltiplas inteligências e o exercício da flexibilidade produtiva (Senai-RJ, 1999a, p. 32)

A metodologia de ensino passou a ser socializada e o ensino se tornou coletivo. $\mathrm{O}$ aluno, ao ingressar num curso profissionalizante, necessariamente deveria estar engajado em uma turma, seguir o ritmo de aprendizagem do coletivo e cumprir um cronograma que vale para todos os aprendizes. Na nossa leitura, o objetivo do SENAI de formar um coletivo, uma turma para a realização da formação profissional é propiciar a socialização deste aprendiz e, assim, reforçar a ideia do trabalho em equipe, que é tão propugnado pelo

\footnotetext{
${ }^{5}$ No método da instrução individualizada, o aluno ingressava num curso profissionalizante sem estar engajado numa turma, ou seja, o ingresso nos cursos de aprendizagem ocorria individualmente. Ao iniciar o curso, o aluno era informado que ele deveria cumprir um determinado número de tarefas que estavam prescritas nos cadernos de instrução das séries metódicas ocupacionais. Os cadernos de instrução eram compostos pelas folhas tarefas que indicavam o que fazer, pelas folhas de operação que mostravam como fazer e pelas folhas de informação tecnológica que demonstravam com quais instrumentos e ferramentas se executaria a atividade proposta. Após o estudo destas folhas, os aprendizes eram arguidos pelo instrutor. O próximo passo era elaboração pelo próprio aluno de um roteiro de trabalho a ser executado na oficina. E, finalmente, o aluno realizava o estágio obrigatório numa indústria e recebia o certificado profissional. As habilidades manuais e o conteúdo eminentemente tecnicista dos cursos profissionalizantes eram a tônica desta metodologia de ensino.
}

Iluminuras, Porto Alegre, v. 14, n. 33, p. 212-228, jul./dez. 2013 
capitalismo. Enfim, o SENAI apontou que era importante incorporar à formação profissional princípios que valorizassem o aprender, a capacidade de decisão e de iniciativa, a cooperação, a autonomia e a responsabilidade, a criatividade e a participação. Segundo o SENAI, a tônica desta nova metodologia se voltou para a capacidade de "aprender a pensar" e a "aprender a aprender, a desaprender e reaprender" (SENAI-RJ, 1999a).

A grade curricular, além das matérias técnicas (habilidades específicas) correspondentes a cada ramo profissional, incorporou disciplinas básicas e instrumentais.

A estrutura curricular que se construiu era dividida em habilidades básicas, habilidades específicas (introdutórias e profissionais) e habilidades de gestão. Segundo o SENAI, as habilidades básicas se remetiam a um:

Conjunto de saberes e de estratégias que visam ao desenvolvimento das múltiplas estruturas de aprendizagem (processos cognitivos, destrezas, atitudes e predisposições) e saberes de caráter instrumental - ferramentas essenciais, no contexto do cotidiano pessoal e profissional para ampliação do conhecimento e para o desenvolvimento do indivíduo como um todo. (Senai-RJ, 1999a, p. 37).

As habilidades específicas estavam relacionadas:

Ao conjunto de saberes técnico-científicos, gerais e específicos, teóricos e práticos, que têm, num primeiro momento, um caráter mais geral e se especializam nos conteúdos profissionais de cada curso; para efeito didático, essas habilidades dividem-se em introdutórias e profissionais. (Senai-RJ, 1999a, p.37)

Já as habilidades de gestão significavam um:

Conjunto de saberes teóricos e práticos, de caráter geral, que fundamentam a análise da realidade concreta - na qual se situam o dilema entre os interesses individuais e coletivos - e orientam o processo de decisão pessoal, assim como as práticas relacionais e sociocomunicativas que facilitem a realização de trabalho cooperativo em equipe e de trabalho autônomo, contribuindo para a compreensão do cotidiano da vida e do mundo do trabalho (Senai-RJ, 1999a, p. 36).

A grande novidade que se apresentou nesta estrutura curricular foram as habilidades de gestão. As habilidades básicas também se apresentaram como uma novidade, porém nosso olhar sociológico se voltou para as habilidades de gestão. Conforme o SENAI, as habilidades de gestão tiveram por escopo "habilitar o trabalhador a atuar em grupo, planejar e administrar melhor o seu trabalho de acordo com elevados padrões de qualidade e segurança, contribuindo assim, para a formação do profissional competente e consciente”. (Senai-RJ, 1998, p. 8)

Iluminuras, Porto Alegre, v. 14, n. 33, p. 212-228, jul./dez. 2013 


\section{Matriz curricular - mecânico de manutenção}

\begin{tabular}{|c|c|c|c|c|}
\hline $\begin{array}{l}\text { Componentes } \\
\text { Curriculares }\end{array}$ & Unidades Curriculares & $\begin{array}{l}\text { Módulo } \\
\text { Básico I }\end{array}$ & $\begin{array}{l}\text { Módulo } \\
\text { Básico II }\end{array}$ & $\begin{array}{l}\text { Módulo } \\
\text { Especial I }\end{array}$ \\
\hline Habilidades Básicas & $\begin{array}{l}\text { Processos Cognitivos } \\
\text { Leitura de Conteúdo } \\
\text { Matemática }\end{array}$ & $\begin{array}{l}40 \mathrm{~h} \\
30 \mathrm{~h} \\
60 \mathrm{~h}\end{array}$ & & \\
\hline $\begin{array}{l}\text { Habilidades Específicas } \\
\text { Introdutórias }\end{array}$ & $\begin{array}{l}\text { Iniciação à Tecnologia } \\
\text { Iniciação ao Desenho } \\
\text { Iniciação à Informática } \\
\text { Tecnologia dos Materiais } \\
\text { Interpretação de Desenho } \\
\text { Medição Industrial }\end{array}$ & $\begin{array}{l}40 \mathrm{~h} \\
40 \mathrm{~h} \\
30 \mathrm{~h}\end{array}$ & $\begin{array}{l}30 \mathrm{~h} \\
40 \mathrm{~h} \\
40 \mathrm{~h}\end{array}$ & \\
\hline $\begin{array}{l}\text { Habilidades Específicas } \\
\text { Profissionais }\end{array}$ & $\begin{array}{l}\text { Tecnologia Máq. Ferramentas } \\
\text { Ajustagem Básica } \\
\text { Eletricidade Básica } \\
\text { Noções de Soldagem } \\
\text { Elementos de Máquinas I } \\
\text { Lubrificação } \\
\text { Tecnologia de rolamentos I } \\
\text { Bombas e compressores I } \\
\text { Pneumática I } \\
\text { Hidráulica I } \\
\text { Organização da Manutenção }\end{array}$ & & & $\begin{array}{l}40 \mathrm{~h} \\
80 \mathrm{~h} \\
80 \mathrm{~h} \\
40 \mathrm{~h} \\
60 \mathrm{~h} \\
30 \mathrm{~h} \\
40 \mathrm{~h} \\
60 \mathrm{~h} \\
80 \mathrm{~h} \\
80 \mathrm{~h} \\
20 \mathrm{~h}\end{array}$ \\
\hline Habilidades de Gestão & $\begin{array}{l}\text { Formas de Organização no Trabalho } \\
\text { Legislação e Normas } \\
\text { Relações Humanas no Trabalho } \\
\text { Higiene e Segurança no Trabalho } \\
\text { Qualidade } \\
\text { Educação Ambiental } \\
\text { Cidadania e Ética }\end{array}$ & $\begin{array}{l}20 \mathrm{~h} \\
20 \mathrm{~h} \\
16 \mathrm{~h} \\
16 \mathrm{~h} \\
16 \mathrm{~h} \\
16 \mathrm{~h} \\
16 \mathrm{~h}\end{array}$ & & \\
\hline \multicolumn{2}{|c|}{ CARGA HORÂRIA P/ MÓDULO } & $360 \mathrm{~h}$ & $110 \mathrm{~h}$ & $610 \mathrm{~h}$ \\
\hline \multicolumn{2}{|c|}{ CARGA HORÁRIA ATUAL } & \multicolumn{3}{|c|}{$1080 \mathrm{~h}$} \\
\hline
\end{tabular}

Fonte: Documento do curso de aprendizagem de mecânico de manutenção, SENAI-RJ, 1999f.

Iluminuras, Porto Alegre, v. 14, n. 33, p. 212-228, jul./dez. 2013 


\section{O material didático do curso de mecânico de manutenção}

Conforme foi dito anteriormente, neste momento iremos descrever o material didático referente ao módulo de habilidades de gestão, que foi uma das grandes novidades da nova estrutura curricular do SENAI do Rio de Janeiro.

Na disciplina Relações humanas no trabalho, o SENAI desenvolveu a questão das relações sociais com os aprendizes. Os temas tratados nesta disciplina foram: relações humanas e o mundo atual: novos tempos, novas atitudes; relações humanas e parceria; comunicação; autoconhecimento; criatividade; liderança; amadurecimento do grupo, administração de conflitos e mudanças e Relações humanas e qualidade de vida.

A matéria Formas de organização do trabalho abordou três temas: o trabalho, a empresa e os empreendedores.

O módulo Legislação e normas tinham por objetivo informar os aprendizes sobre direitos e deveres, enquanto trabalhadores e cidadãos, e as normas técnicas a serem seguidas no mundo do trabalho.

$\mathrm{Na}$ disciplina Cidadania e ética, o SENAI declarou que "a idéia é tratar da ética cidadã relacionando-a ao mundo do trabalho" (Senai-RJ, 1999d, p. 9). A cidadania na visão do SENAI "diz respeito à participação individual e coletiva nos assuntos públicos, aos deveres e direitos comuns a todos, ao exercício da liberdade e da superação da necessidade" (Senai-RJ, 1999 d, p. 9). Quanto a ética, o SENAI reiterou que é “a capacidade da pessoa tomar atitudes e posições segundo seu próprio juízo de valor, considerando os pontos de vista envolvidos e os aspectos de cada situação" (Senai-RJ, 1999d, p. 9). Para o SENAI, ser cidadão significa ter um trabalho. A cidadania brasileira construída a partir da esfera do trabalho na Era Vargas continua alimentando a definição de cidadania do SENAI. Esta disciplina fez um grande passeio pela História do Brasil, no período compreendido entre 1973 a 1998.

Em Higiene e segurança no trabalho, os aprendizes foram informados como deveriam proceder quanto à higiene pessoal e a aparência pessoal no local de trabalho. Além disso, receberam esclarecimentos a respeito do que se caracteriza como acidente de trabalho e seus direitos diante de tal acontecimento. E, por fim, foi abordado como os trabalhadores devem proceder para se manterem seguros no trabalho (Senai-RJ-DE-DFD-SPP, 1995a). 
Na disciplina Qualidade foram oferecidas informações técnicas aos aprendizes sobre a organização do processo de trabalho com o escopo de maximizar a produção. Para lograr tal objetivo, os aprendizes devem obedecer aos critérios internacionais de qualidade (SenaiRJ-DE-DFD-SPP, 1995b).

Em Educação ambiental houve uma preocupação em conscientizar e sensibilizar os aprendizes em relação às questões pertinentes ao meio ambiente.

\section{Instrutores e aprendizes: percepção a respeito das mudanças no SENAI e no mundo do trabalho}

A partir dos depoimentos dos instrutores e aprendizes apreendemos as representações destes a respeito do novo método de ensino, da nova estrutura curricular, das habilidades, dos valores, princípios engendrados pelo SENAI e das mudanças ocorridas na esfera do trabalho.

\section{A) Instrutores}

O acréscimo das habilidades básicas e, sobretudo das habilidades de gestão à estrutura curricular e a introdução da metodologia socializada, foram novidades vividas de uma forma muito difícil e conflituosa pelos instrutores, gerando um confronto entre o que foi vivenciado anteriormente e a nova perspectiva. Levando em consideração que esses instrutores estavam há mais de 25 anos trabalhando no SENAI quando foi realizada a pesquisa de campo em 1999, eles eram adaptados ao método individualizado de ensino e a ministrar apenas as disciplinas técnicas (habilidades específicas). A ruptura empreendida pelo SENAI representou uma mudança de referencial desses instrutores. O método individualizado foi substituído pelo método socializado e instrutores passaram a ministrar as aulas de habilidades de gestão. Os valores, os princípios e habilidades que deveriam ser trabalhados com os aprendizes não se remetiam mais ao fordismo e, sim, à nova etapa do 
capitalismo que muitos estudiosos, entre eles Piore e Sabel (1984), denominam de especialização flexível ${ }^{6}$.

Segundo os relatos dos instrutores, a capacitação para o novo método não ocorreu de forma contínua, houve algumas interrupções e o SENAI não exerceu um controle rígido deste processo de requalificação dos instrutores.

Os operários, nós, trabalhadores não fomos treinados. De repente abriu-se a porta e entrou isso tudo. Quem vai mexer? Ninguém sabe. Por quê? Porque tinha que haver todo um processo de troca, de investimento das empresas. Mas o que o empresário quer? $O$ empresário, ele quer facilidade. Ele quer que você opere numa máquina, resolva todos os problemas para ele e ganhe metade da metade da metade de um salário. Ele não quer investir num treinamento, ele não quer investir num aperfeiçoamento, ele não quer investir em nada disso. Ele quer que você resolva o problema dele e dê lucro para ele, até entende, mas precisa fazer um investimento, precisa. (Instrutor 1 da área de metalmecânica do SENAI, grifos nossos).

Percebemos uma resistência dos instrutores diante da nova metodologia e do novo currículo do SENAI, das mudanças da reestruturação produtiva, dos novos valores, princípios e habilidades requeridos pelo capital. $\mathrm{O}$ contraste entre as experiências e vivências do passado, sobretudo do estilo de vida ${ }^{7}$ fordista e o tipo de saber acumulado desta época e o novo horizonte que se apresentou, trouxe à tona um sentimento e uma necessidade por parte destes instrutores de preservar a memória do SENAI.

A ameaça de desemprego em função das inovações e, mais uma vez, a pouca atenção do SENAI em relação à capacitação de seus quadros causaram ressentimento nos instrutores.

Os instrutores detectaram que há necessidade de um maior empenho de sua parte atualmente, uma vez que a dinâmica de ensino mudou. Na metodologia socializada, o instrutor deve se fazer mais presente, pois ele é o responsável pela interação dos alunos e, também, por suscitar o sentimento de equipe entre os aprendizes. Apesar da dificuldade de lidar com o novo, alguns instrutores conseguiram perceber aspectos positivos na nova estrutura curricular, principalmente no que concerne às habilidades de gestão:

\footnotetext{
${ }^{6}$ C.f. Piore, M., Sabel C. The second industrial divide: possibilities for prosperity. Nova Iorque: Basic Books, 1984.

${ }^{7}$ Para uma discussão sobre estilo de vida, veja Bourdieu, 1994.
} 
A vantagem é que abriu-se um leque, começou a dar mais informações a respeito de cidadania, de processos cognitivos, essas coisas todas. Eu acho que foi enriquecido, embora seja bastante rápido, né? Eu acho que foi um ganho, houve um ganho, houve um ganho. Você tendo acesso à informação, as portas vão se abrindo. Agora se você não tem, nem sabe que existe, como é que vai ficar? Fica complicado, fica difícil. Você está rotulado a entrar numa fábrica, a trabalhar na linha de produção, nas condições muitas vezes subumanas e a viver daquele salário e acabou. Aí você vai ter uma família, você vai fazer operariozinho, a mesma coisa, tudo bem! Aí vira uma coisa, uma cadeia direta (Instrutor 1 da área de metal-mecânica do SENAI).

O SENAI pulverizou as profissões na nova estrutura curricular para que, por exemplo, o mecânico de manutenção tenha noções de ajustagem, de eletricidade, soldagem, de hidráulica e pneumática, etc. Esta pulverização teve por objetivo a formação dos trabalhadores ditos polivalentes. O SENAI depois do Projeto Logos não formava mais torneiro mecânico, ajustador mecânico e fresador, pois a especialização cedeu lugar às noções fragmentadas de profissões correlatas. Em função disto, a carga horária das disciplinas diminuiu e a velocidade do curso aumentou, a fim de abarcar noções das várias profissões. A fragmentação e velocidade dos cursos são criticadas vorazmente pelos instrutores. Este instrutor percebeu que a fragmentação e a velocidade vão produzir trabalhadores que recebem um pouco de conhecimento de cada profissão, porém não exercerão com apuro nenhuma das profissões:

\footnotetext{
A desvantagem é a velocidade conforme é dado, eu acho que é isso. A desvantagem é essa, é muito rápido e essa carga horária ela se torna muito reduzida. Eles começaram a reduzir muito a coisa, essa foi a desvantagem porque hoje tá se precisando, o aluno não pode... é um produto nosso. Os aprendizes não podem ficar muito tempo aqui dentro. $\mathrm{O}$ que eles querem agora? Eles não querem mais ninguém com formação completa, eles querem só com informações rápidas, a respeito das áreas, o que tá acontecendo é isso! Por exemplo, o curso aqui no SENAI de tornearia era de 34 tarefas, passou para 20 tarefas. Hoje mecânico de manutenção, de tornearia ele faz 4 tarefas. Precisa conhecer de tornearia para você chegar a conclusão de isto tem alguma coisa que não vai bater? Precisa? Não, não precisa, tá claro! Hoje a gente tá dando informações sucintas. É o primeiro empurrão, você pega ou você morre ou você vai pegar no tranco ou você não pega, entendeu? Aí fica complicado. (Instrutor 1 da área metal-mecânica do SENAI)
}

Em todas as entrevistas, os instrutores travaram um diálogo interno que eles tinham que aceitar e introjetar o novo método de ensino. É claro que esta "aceitação" se exerce de forma coercitiva, sob pena de serem demitidos, caso não se adaptem. Os instrutores, sob a pena de perderem o emprego, apreenderam que tinham que se adaptar continuamente diante das mudanças. Isto fez com que os instrutores compartilhassem as mesmas perspectivas dos trabalhadores das outras esferas, a incessante busca pelo aprimoramento profissional e 
assimilação das mudanças e, dessa maneira, haveria possibilidade de assegurarem seus empregos.

As críticas engendradas pelos instrutores em relação à polivalência, e as consequências que esta traz em seu bojo, surgem mais uma vez de forma contundente nos trechos a seguir:

O mecânico de manutenção é... o, empregador não quer ver o funcionário parado. Essa é a grande realidade. O polivalente é o homem de 7 instrumentos. Ele serve para consertar um equipamento seja parte elétrica, hidráulica, mecânica, eu entendo desse ponto de vista. (Instrutor 3 da área metal-mecânica do SENAI)

Olha, esse negócio de polivalente é uma conversa muito forte do empresariado porque num país que está se querendo emprego, como é que quer que o cara faça três, quatro coisas? Você quer tirar vaga de mais dois, três, quatro, entendeu? Como? Não tem condições disso! Se precisa empregar as pessoas, agora eu vou querer que o cara resolva tudo. O que estão fazendo agora é disposição em ilha, bota o cara no meio, ele prende aqui, ali, liga essa, vai para essa, vai para essa, põe para essa e volta para essa. Ele não tem tempo nem de ir ao banheiro se bobear. Por que ele trabalha? Porque se ele não se sujeitar a isso, ele vai ficar em casa esperando o que? Cair do céu? E os compromissos? E a família fica onde? Então tem que entrar, não tem jeito. (Instrutor 1 da área metal-mecânica do SENAI, grifos nossos).

A intensificação do trabalho foi mencionada nas apreensões destes instrutores sobre a polivalência e o novo lay out da produção em ilha. Os instrutores lançaram observações em relação ao trabalho em equipe. Eles ressaltaram que o perfeito entendimento entre as pessoas que compõem a equipe, tão demandado pelo capitalismo, tem por objetivo simplesmente o êxito da produção.

Hoje se fala em equipe, como se fala de equipe há bastante tempo, hoje a ideia de equipe mudou. Hoje a equipe são todo mundo trabalhando. Existe uma hierarquia dentro da equipe, mas a equipe é importante porque tá o conjunto, uma harmonia, um entendimento. Essa equipe tem que tá desarmada, ele tem que tá... um chegar ao outro em prol de um objetivo que é a produção, não sei que vai ser, mas a equipe se der certo, a equipe toda acertou, mas der errado, a equipe toda errou. (Instrutor 1 da área metalmecânica do SENAI)

Conforme foi explanado, os instrutores vivenciaram de uma forma conflituosa o processo de ruptura do SENAI com a antiga metodologia de ensino. Eles se mostraram extremamente resistentes às mudanças impingidas. Como o novo método de ensino do SENAI é uma consequência das novas demandas do capitalismo, os instrutores se mostraram reticentes também em relação à nova arquitetura do capital. Eles se posicionaram criticamente frente à conjuntura de inovações do SENAI e das mudanças do 
capitalismo e do mundo do trabalho. As críticas engendradas pelos instrutores estavam relacionadas, basicamente, a duas questões: primeira, a ameaça da perda do estilo de vida fordista e a segunda, a percepção da maximização da exploração do trabalhador industrial.

Estes indivíduos se construíram como trabalhadores da indústria e como instrutores tendo como referencial o fordismo com todos os seus princípios, valores e habilidades. As inovações que se apresentaram foram percebidas pelos instrutores como uma ameaça ao estilo de vida que haviam construído. A ameaça podia se concretizar em realidade através da perda do emprego. Os instrutores estavam inseridos neste campo de luta, cuja realidade se remeteu às inovações do processo de formação profissional do SENAI e as novas demandas do capitalismo. As estratégias de ação destes indivíduos estavam relacionadas à distribuição de capitais específicos e à posição que ocupam no interior do campo. A percepção da ameaça do estilo de vida trouxe em seu bojo a apreensão da maximização da exploração do trabalhador. Pontualmente, os instrutores apontaram que a fragmentação das profissões e a condensação em um único curso profissionalizante tiveram por objetivo produzir trabalhadores que deveriam operar várias máquinas e realizarem um maior número de tarefas possíveis, porém sem estarem suficientemente qualificados para executarem tal trabalho. E, por fim, os instrutores apreenderam que o trabalho em equipe tem por fim último o êxito da produção, que é estimulado pelo discurso empresarial de que todos os trabalhadores devem se ajudar.

\section{B) Aprendizes}

Como foram introduzidas ao mundo da profissionalização por intermédio da metodologia de ensino socializada, as representações do processo de formação profissional destes aprendizes então se autocentraram nesta nova metodologia. De uma maneira geral, os aprendizes consideraram que este método era melhor e teceram comentários explicando os motivos de acharem melhor, porém tendo como referência as representações elaboradas por seus parentes a respeito da antiga formação profissional do SENAI. 
Porque você tem um ano e quase quatro meses, você tem a turma, você começa com essa turma, você termina com ela. Você pega amizade com as pessoas, consegue até se entrosar melhor no trabalho, isso é trabalho novo, se eu tivesse no individualizado, eu não conheceria eles, então como eи vou trabalhar? Coто eи vou conseguir dialogar com eles, se eu não conheço? É mais difícil, por isso é que é bom o socializado, eu acho melhor, não sei como foi o individualizado, mas acho melhor o socializado, pelo que meu pai fala. (Aprendiz 1 de mecânico de manutenção do SENAI, grifos nossos).

O espírito de equipe e cooperação, valores que atualmente são inculcados pelo SENAI, perpassam as falas dos alunos. "Pegar amizade", "esperar todo mundo terminar" e "se entrosar melhor no trabalho" são aspectos recorrentes nestes depoimentos e, segundo os aprendizes, isto só foi possível pelo agrupamento em turmas.

Juntamente com o espírito de equipe e a cooperação, a polivalência é um valor e uma habilidade demandada pelos cursos do SENAI. Os aprendizes, ao refletirem sobre a polivalência, salientaram que esta demanda tem por objetivo a contenção de custos e o incremento da produção:

É aquele trabalhador que faz tudo, né? Mecânico de manutenção agora, antigamente tinha a área de tornearia, ajustagem e fresa, agora a gente faz tudo. Sou mecânico de manutenção, só que eu mexo aqui, mexo ali, tem que saber tudo. Para chegar na empresa e trabalhar em tudo também. Meu pai começou como torneiro especializado, na seção dele são dez máquinas... Na seção do meu pai são dez máquinas e dez pessoas, agora meu pai sozinho já fica em 5 máquinas, entendeu? Polivalente pelo que eu entendi é para diminuir mais né? Diminui o custo da empresa, gasta menos funcionário e tem profissional que sabe mexer em tudo. No caso do SENAI, ele tá formando esses polivalentes que é o operador de processo mecânico e o mecânico de manutenção (Aprendiz 1de mecânico de manutenção do SENAI).

Porque reduz o número de empregados, eles têm mais lucro, né?(Aprendiz 2 de mecânico de manutenção do SENAI).

Em termos de estrutura curricular, os aprendizes apreenderam que a polivalência é "aprender mais em menos tempo":

Esses cursos separados [torneiro, fresador, ajustador] foram extintos. Agora é um curso que você faz isso tudo, ou seja, você aprende mais em menos tempo porque tinha que fazer um curso de torneiro. Caso você quisesse aprender outra coisa, era mais outro tempo para você fazer o de fresador. Assim não, você já sai com um currículo, já vai para a empresa sabendo fazer de tudo um pouco, você sabe fresar, você saber tornear uma peça. (Aprendiz 3 de mecânico de manutenção do SENAI)

Levando em conta que as experiências, vivências, percepções e representações destes aprendizes estão circunscritas à vida de estudante e não possui ainda experiência de

Iluminuras, Porto Alegre, v. 14, n. 33, p. 212-228, jul./dez. 2013 
trabalho, eles se mostraram bastantes receptivos à possibilidade de "aprender mais em menos tempo" e, teoricamente, estarem aptos a operarem mais de uma máquina e, de acordo com esta visão, serem polivalentes. Os aprendizes levantaram apenas parte dos efeitos da polivalência: contenção de custos, maximização do lucro e redução de trabalhadores. Eles não atentaram para outros efeitos da qualificação profissional que foi realizada através da aprendizagem de fragmentos e noções que condensam várias profissões em um único curso profissionalizante. Outro possível efeito da polivalência é o débil conhecimento para executar com apuro as operações das várias profissões supostamente aprendidas nos cursos de aprendizagem.

Em relação à intensificação do trabalho, os aprendizes opinaram que a polivalência não contribuiu para aumentar o volume e o ritmo de trabalho porque os equipamentos são à base da microeletrônica e isto reduziria o trabalho braçal. Na realidade, o trabalho manual foi reduzido, porém aumentou o número de operações a serem executadas em equipamentos com comando numérico computadorizado (CNC) e os controladores lógicos programáveis (CLP).

\begin{abstract}
[Aumentou o ritmo de trabalho?] Não, sabe por quê? Porque as máquinas são CNC, comando numérico, igual aquela máquina ali. Você vai põe a peça, programa ela, deixa ela fazer o resto, vai programa ela... antigamente era um trabalho muito braçal. Estas máquinas são todas antigas, olha como fica, eles puxam daqui, puxam dali, outro metendo a mão ali porque é máquina antiga. Antigamente tinha que ser um, realmente, em cada máquina. Agora não, ele só aperta um botão ali e programa ali e programa ali e volta, vai tirando as peças, vai tirando as peças e volta. Não há necessidade, se fosse tua empresa, você não vai ter necessidade de colocar vários trabalhadores se um só pode fazer tudo isso tudo. (Aprendiz 1 de mecânico de manutenção do SENAI)
\end{abstract}

Thompson (1987), ao estudar as inovações que estavam sendo introduzidas na indústria inglesa durante a primeira metade do século XIX, nos forneceu algumas pistas para pensar o depoimento que estamos analisando. As questões analisadas por este autor remetem às inovações tecnológicas, ao desaparecimento das antigas habilidades e especialidades e o surgimento de novas habilidades e especialidades. Thompson nos alertou que, ao observar o surgimento de novas habilidades e o desaparecimento de outras, corremos o risco de esquecer que as antigas e as novas habilidades são quase sempre protagonizadas por pessoas diferentes. 
Mesmo nos casos em que uma antiga especialidade fosse substituída por outra, que exigisse uma habilidade igual ou mesmo maior, raramente encontramos na nova algum trabalhador que se tenha transferido da antiga, ou alguém que deixasse a produção doméstica pela industrial. A insegurança e a hostilidade em relação à maquinaria e às inovações não resultavam simplesmente de preconceitos, nem de (como pensavam as autoridades) um conhecimento insuficiente da economia política. $\mathrm{O}$ aparador ou $\mathrm{o}$ cardador sabiam muito bem que a nova maquinaria, embora pudesse proporcionar um emprego especializado ao seu filho ou ao filho de qualquer outro trabalhador, nada tinha a lhe oferecer. As vantagens da 'marcha do progresso' pareciam sempre beneficiar a outra pessoa. (Thompson, 1987, v. II, p.89).

E por último gostaríamos de apontar como um dos aprendizes reagiu diante do antagonismo entre o trabalho braçal e o trabalho intelectual:

Depende da minha situação que eu tiver. Quando eu terminar o meu $2^{\circ}$ grau, esse meu ano é o último, que eu tô fazendo agora que é informática. Não tô fazendo mais enfermagem, se eu conseguir um emprego em outro lugar e eu achar que eu dou melhor na informática que na mecânica, eu vou para informática, agora se não, não tem problema. É mais uma opção para mim. [A informática pode te dar uma condição de vida melhor?] Eu não sei, o ruim é que informática é mais trabalho mais parado, só na cabeça. Olha aqui a minha mão, até que tá limpinha, eu lavei, mas aqui você suja muito. É muito trabalho. É muito esforço. A informática não é só aqui na cabeça, mas eu prefiro. (Aprendiz 1 de mecânico de manutenção do SENAI)

Este aprendiz, ao refletir sobre seu status e a posição que ocupa na sociedade e que ocupará no mundo do trabalho se for trabalhar como mecânico de manutenção, preferia trabalhar como técnico em informática. Ao contrastar o estilo de vida de seu pai, operário da indústria metal-mecânica, com a possibilidade de outro estilo de vida que a função de técnico de informática possa lhe proporcionar, este aprendiz escolheu o segundo estilo de vida.

Trouxemos, portanto estas observações sobre as representações das experiências dos instrutores e aprendizes com o escopo de contribuir para um maior entendimento da dimensão subjetiva da então nova metodologia de ensino e da nova grade curricular que se estabeleceu após a experiência do Projeto Logos em 1995 no SENAI do Rio de Janeiro.

Temos claro que o SENAI, na condição de uma das mais importantes entidades de fomento à mão-de-obra industrial, é uma estrutura objetiva cujo escopo é inculcar valores, ideias, habilidades que estejam em consonância com o capitalismo na sua atual fase. Mas o que temos que ter mais claro, ainda, é que o SENAI é apenas mais um componente no processo de formação e construção do trabalhador industrial, além, é claro, de outros componentes, tais como origem familiar, experiências herdadas dos pais, inserção ou futura 
inserção no mercado de trabalho e vivências decorrentes disto entre outros. Este processo de se fazer e se construir trabalhador industrial é contínuo, ou seja, podemos dizer que é um incessante processo de se (re)formar e se (re)construir.

\section{Considerações finais}

Escolhemos o então chamado curso básico (antigo curso de aprendizagem) de mecânico de manutenção para mapearmos os valores, as habilidades e os princípios inculcados pelo SENAI, através do Projeto Logos, nos aprendizes.

Através da análise do material didático das habilidades de gestão e das entrevistas com os aprendizes, com os instrutores, com as técnicas da área de educação do SENAI, com os representantes da indústria e com um operário (ex-aluno do SENAI), detectamos os valores, habilidades e princípios que permearam a formação profissional engendrada pelo SENAI. A polivalência, o trabalho em equipe, a predisposição do trabalhador em resolver problemas, a figura do líder, a ausência de conflito, a responsabilidade, a participação, a criatividade, o compromisso com o processo de produção, aprimoramento profissional do trabalhador, estes foram os novos valores, as novas habilidades e os novos princípios identificados por nós.

Ao analisar as representações dos instrutores e aprendizes, o nosso objetivo era entender como estavam sendo apreendidas por eles as mudanças no processo produtivo e, principalmente, as mudanças relativas à formação profissional oferecida pelo SENAI. Em função disto, concluímos que apesar do SENAI ser uma entidade que tem o poder de engendrar valores e princípios, os instrutores se mostraram mais resistentes e críticos frente a esta conjuntura que se apresentou, além de a terem vivenciado de uma forma conflituosa. Já os aprendizes se mostraram mais receptivos, sem restrições às novas habilidades, valores e princípios da atual fase do capitalismo. Na nossa análise, consideramos que esta aceitação dos novos valores deve-se ao fato destes aprendizes ainda serem estudantes. Precisamos ressaltar que estes aprendizes não tinham experiência de trabalho e iriam se inserir no mercado de trabalho após o término do curso de mecânico de manutenção no SENAI.

Os mecanismos de funcionamento do capitalismo na década de 1990 se mostraram duplamente perversa. Primeiro lugar, porque intensificou o ritmo de trabalho e se apropriou 
do saber tácito dos trabalhadores através das novas habilidades, princípios e valores cultuados; e, em segundo lugar, porque escamoteou estes efeitos através destes mesmos princípios e valores demandados. A lógica da maximização da exploração do trabalho persiste na especialização flexível, porém é exercida de forma sutil.

Temos claro que o SENAI, enquanto uma das mais importantes entidades de fomento à mão-de-obra industrial é uma estrutura objetiva, cujo escopo é inculcar valores, idéias, habilidades que estejam em consonância com o capitalismo na sua atual fase. Mas o que devemos ter mais claro ainda é que o SENAI é apenas mais um componente no processo de formação e construção do trabalhador industrial, além, é claro, de outros componentes, tais como origem familiar, experiências herdadas dos pais, inserção ou futura inserção no mercado de trabalho e vivências decorrentes disto entre outros. Este processo de se fazer e se construir trabalhador industrial é contínuo, ou seja, podemos dizer que é um incessante processo de se (re)formar e se (re)construir.

\section{Referências}

ARAÚJO, Ronaldo Marcos de Lima. "As novas "qualidades pessoais" requeridas pelo capital”. In: Trabalho e Educação, Belo Horizonte, Núcleo de Estudo sobre o Trabalho e Educação, nº 5, jan-jun, 1999.

ASSIS, Marisa de. "A educação e a formação profissional na encruzilhada das velhas e novas tecnologias". In: FERRETI, Celso (org.). Novas tecnologias, trabalho e educação: um debate multidisciplinar. Petrópolis: Vozes, 1994.

BOURDIEU, Pierre. "Gostos de classe e estilos de vida". In: Ortiz, Renato. Bourdieu. São Paulo : Ática, 1994.

FRIGOTTO, Gaudêncio. "As mudanças tecnológicas e educação da classe trabalhadora: politecnia, polivalência ou qualificação profissional?" (Síntese do simpósio). In: MACHADO, Lucília Regina de Souza; NEVES, Magda de Almeida; FRIGOTTO, Gaudêncio et. al. Trabalho e educação. Campinas: Papirus/CEDES; São Paulo: ANDE/ANPED, (Coletânea CBE), 1992.

MACHADO, Lucília Regina de Souza. "Mudanças tecnológicas e a educação da classe trabalhadora". In: FERRETI, Celso (org.). Novas tecnologias, trabalho e educação: um debate multidisciplinar. Petrópolis: Vozes, 1992.

PIMENTA, Solange Maria. "Participação e qualificação: uma nova sincronia de gestão". Trabalho e Educação, Belo Horizonte, Núcleo de Estudo sobre o Trabalho e Educação, nº 5, jan-jun, 1998. 
PIORE, M., SABEL, C. The second industrial divide: possibilities for prosperity. Nova Iorque: Basic Books, 1984.

SENAI-RJ-DE-DFP. Projeto Logos. Rio de Janeiro, 1994.

SENAI-RJ-DE-DFD-SPP. A qualidade na vida e no trabalho; higiene e segurança do trabalho. (Edição preliminar para o Projeto Logos), 1995a.

SENAI-RJ-DE-DFD-SPP. A qualidade na vida e no trabalho, qualidade e produtividade. (Edição preliminar para o Projeto Logos), 1995b.

SENAI-RJ. Relações humanas no trabalho, habilidades de gestão. Rio de Janeiro, GEP/DIPRE. (Série Documentos Orientadores), 1998.

SENAI-RJ. Educação profissional; a concepção do SENAI-RJ. Rio de Janeiro, GEP/DIPRE. (Série Documentos Orientadores), 1999a.

SENAI-RJ. Formas de organização do trabalho, habilidades de gestão. Rio de Janeiro, GEP/DIPRE. (Série Documentos Orientadores), 1999 b.

SENAI-RJ. Legislação e normas, habilidades de gestão. Rio de Janeiro, GEP/DIPRE. (Série Documentos Orientadores), 1999c.

SENAI-RJ. Cidadania e ética, habilidades de gestão. Rio de Janeiro, GEP/DIPRE. (Série Documentos Orientadores), 1999d.

SENAI-RJ. Educação ambiental, habilidades de gestão. Rio de Janeiro, GEP/DIPRE. (Série Documentos Orientadores), 1999e.

SENAI-RJ. - Documento Curso de aprendizagem de mecânico de manutenção. Rio de Janeiro. (versão preliminar), 1999f.

SENAI - Departamento Nacional. Catálogo nacional de cursos técnicos do SENAI. Brasília, 2010.

THOMPSON, Edward P. A formação da classe operária. Rio de Janeiro: Paz e Terra, 1987. v. II.

Recebido em: 05/08/2013

Aprovado em: 10/08/2013 